\title{
Management of late/very late stent thrombosis: Utility of intravenous ultrasonography (IVUS) in clinical practise
}

\author{
Geç/çok geç stent trombozu yönetimi: Intravenöz ultrasonografi (IVUS)'nin \\ klinik kullanımda yararlılı̆̆
}

Emre Yalçınkaya*, Barış Bugan, Yalçın Gökoğlan, Erkan Yıldırım

Department of Cardiology (E. Yalçınkaya, MD, Y. Gökoğlan, MD, E. Yıldırım, MD), Gulhane Military Medical Faculty, TR-06018 Ankara, Cardiology Clinic (B. Bugan, MD), Malatya Army Hospital, TR-44080 Malatya

Geliş tarihi/Received: January 18, 2013; Kabul tarihi/Accepted: January 20, 2013

*Corresponding Author:

Dr. Emre Yalçınkaya, Kardiyoloji Anabilim Dalı, Gülhane Askeri Tıp Akademisi, TR-06018 Ankara. E-mail: dremreyalcinkaya@gmail.com

To the editor

We read with great interest the article by Aksu et al. [1] on the management of very late bare metal stent thrombosis. They performed intracoronary thrombus aspiration and inflated balloon in-stent for restenosis.

During percutaneous coronary interventions, interventionalists have often to deal with thrombus-laden lesions in coronary vessels. Plaque characteristics and distribution, severity and extent of calcification, arterial remodeling and the presence of dissection or thrombi can affect the decision to use a particular treatment before and after PCI. Clear identification of the characteristics of culprit vessels can help to improve clinical outcomes after interventions [2].

While the mechanism of stent thrombosis is yet to be completely understood, stent fracture and/or late acquired stent apposition could set the stage for late stent thrombosis (LST). Some types of late-acquired stent malapposition are caused by positive vessel remodeling due to biological reactions to the stent, which may allow motion and/or kinking of the stent, leading to stent fracture. Alternatively, stent fracture can lead to local mechanical irritation of the vessel, which may lead to stent malapposition. Exposure of a free metal strut after fracture into the vessel lumen could trigger platelet activation, stent thrombosis and subsequent myocardial infarction.

Intravascular ultrasound (IVUS) is a useful diagnostic tool for the assessment of lesion severity leading to revascularization, selection of the revascularization strategy and assessment of lesion composition leading to a change in interventional strategy and can contribute to reaching an optimal decision for intervention $[3,4]$. In this case, if had considered, an IVUS study may have revealed late-acquired stent malapposition was highly prevalent in patients with LST.

In addition, in real world, most very late stent thrombosis cases are associated with discontinuation of anti-platelet agents due to dental procedure or non-cardiac surgery and it appears more closely related to discontinuation of aspirin. In stent thrombosis cases, despite ongoing anti-platelet agent, resistance must be considered and evaluated to avoid future complications. 


\section{References}

1. Aksu T, Başer K, Durukan MK, Şen T, Güray Ü. Very late thrombosis of a bare metal stent despite ongoing aspirin therapy after 10 years of implantation. Cumhuriyet Med J 2012; 34: 481-4.

2. Iyisoy A, Celik M, Celik T, Yuksel UC. The role of intravascular ultrasound guidance in the treatment of intramural hematoma probably caused by spontaneous coronary artery dissection in a young woman with acute anterior myocardial infarction. Cardiol J 2012; 19: 532-5.

3. Kosonen P, Vikman S, Jensen LO, Lassen JF, Harnek J, Olivecrona GK, Erglis A, Fossum E, Niemelä M, Kervinen K, Ylitalo A, Pietilä M, Aaroe J, Kellerth T, Saunamäki K, Thayssen P, Hellsten L, Thuesen L, Niemelä K. Intravascular ultrasound assessed incomplete stent apposition and stent fracture in stent thrombosis after bare metal versus drug-eluting stent treatment the Nordic Intravascular Ultrasound Study (NIVUS). Int J Cardiol 2012.

4. Armstrong EJ, Kwa AT, Yeo KK, Mahmud E, Javed U, Patel M, Shunk KA, Macgregor JS, Low RI, Rogers JH. Angiographically confirmed stent thrombosis in contemporary practice: Insights from intravascular ultrasound. Catheter Cardiovasc Interv 2012 